\title{
26 The Parkes Elvis Festival: Attendee and Host Community Perspectives
}

\section{Katie Schlenker, Carmel Foley and Eve Carroll-Dwyer}

\section{Introduction}

Each year, up to 20,000 people descend upon the rural town of Parkes, $365 \mathrm{~km}$ west of Sydney, to attend the Parkes Elvis Festival. Initiated in 1993 by a group of locals who were Elvis Presley fans, the annual festival has grown from the humble beginnings of a one-day event with a few hundred attendees to a five day festival.

In a bid to assist the festival organisers to understand the impacts of the Parkes Elvis Festival on both attendees and the host community, researchers designed a set of survey instruments to deliver a comprehensive evaluation of the social and economic impacts of the festival. Research was carried out in 2010 and separate surveys were conducted for festival organisers, attendees and local residents. After a brief explanation of the festival, and the man it is inspired by, this chapter explores the methods used to collect data before outlining the results. The results are divided into two key sections, attendees' perceptions, and host community perceptions.

First we profile the demographics, motivations and experience of festival attendees. Second, we profile the perceptions of the host community with respect to both the economic and social impacts of the festival. The surveys demonstrate the overwhelming goodwill and enthusiasm for the festival, by both the host community and attendees. Results show that the festival attracts a mix of first time and repeat visitors, and that many of the returning attendees do so to catch up with friends made at previous festivals. For residents, regardless of whether they attend or not, the large majority understand the economic, tourism and community benefits generated by the festival.

\section{Elvis and the Parkes Elvis Festival}

Known as the 'King of Rock and Roll', Elvis Aaron Presley was born in Tupelo Mississippi, in 1935 and became one of the most influential and celebrated singer/ 
entertainers of the 20th century. His momentous career lasted over 20 years, and ended with his premature death at the age of 42. Elvis's career spanned both music and film and will be forever associated with the rise and evolution of Rock n' Roll. The festival is timed to coincide with Elvis' birthday (January 8th) and includes a multitude of Elvis impersonators who provide official featured showcases, as well as the more informal busking Elvises. Alongside the musical entertainment there are over 120 activities spread throughout the town of Parkes, each inspired by various facets of Elvis' career. Popular activities include a street parade, vintage car exhibition, rock and roll dancing, a poets' breakfast - where odes to Elvis can be delivered - market stalls, a Miss Priscilla dinner (honouring Elvis's wife, Priscilla Presley, and with a new 'Miss Priscilla' being crowned each year), an interdenominational gospel service and a mass renewal of wedding vows (http://www.parkeselvisfestival.com.au/).

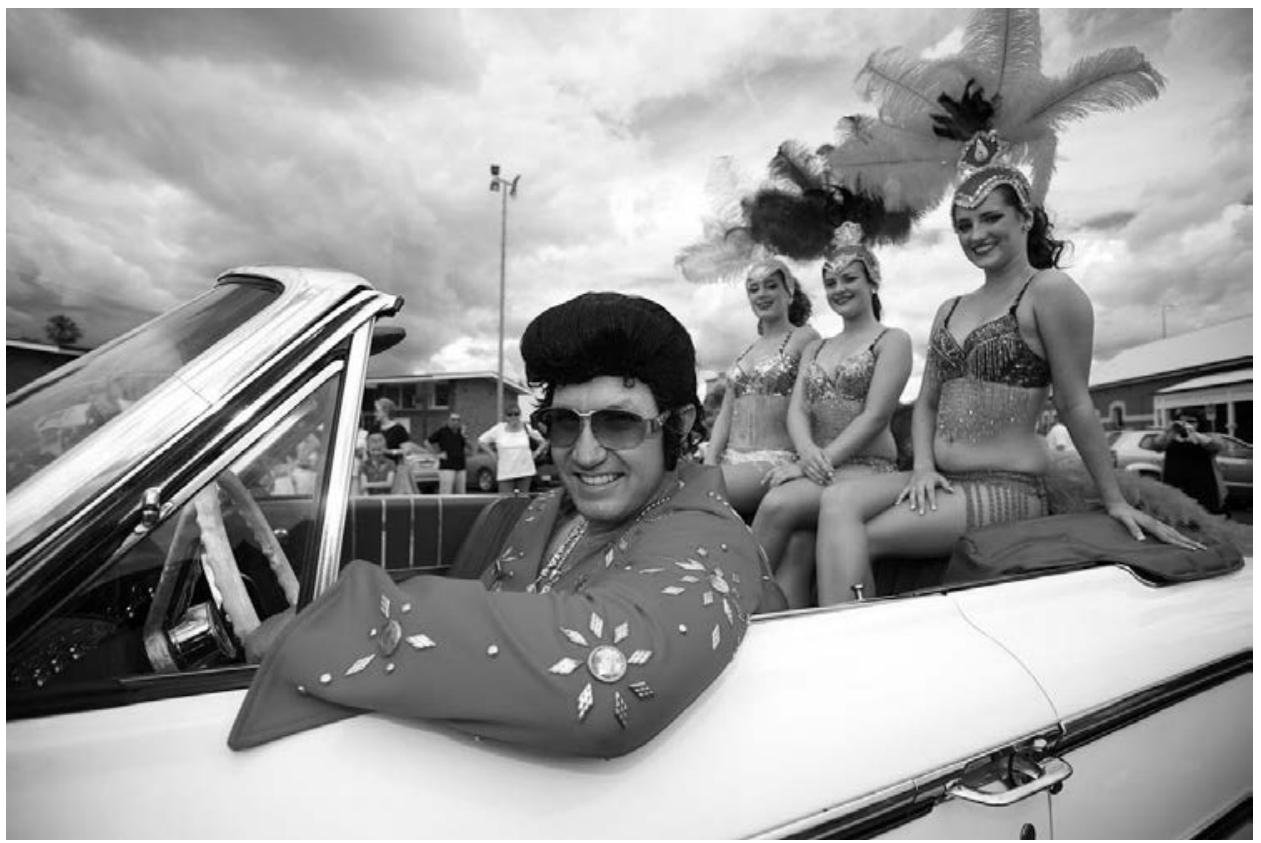

Figure 26.1: Elvis impersonator at the Parkes Elvis Festival. @ Parkes Elvis Festival

The whole town of Parkes embraces the theme with a range of business operators getting involved. The main shopping streets are festooned and retailers take up the festival theme, decorating their shop windows for example, 'Love me Tender lamb chops at \$10.99 a kilo!' (Jonson, et al. forthcoming). Loud speakers and buskers line the streets and a jovial ambiance radiates throughout the, otherwise quiet, country town. A key feature that fortifies the spirit, and eccentricity, of the event is that attendees are not simply spectators at the festival - they also participate and take an active role as they dress up in outfits inspired by Elvis, be it his music, movies or the rock $n^{\prime}$ roll era. Individuals address their fellow participants/entertainers as if they are real characters. Thousands of Elvises and 
Pricillas walk the streets engaging with each other, and their 'fans' in full character in an otherwise unremarkable, Australian rural town.

As a region whose main economic staple is farming, and is otherwise best known for its CSIRO satellite dish (featured in the classic Australian movie The Dish, released in 2000), Parkes does not hold any obvious connections to music, or indeed Elvis himself. Despite the festival's unconventionality, its growth and sustained success attracted sponsorship from companies such as CountryLink, Coca Cola, Clubs NSW, Rex Regional Express, Anderson First National Real Estate (Foley et al., 2011). Parkes has become widely known as the 'Elvis Capital of Australia' and the festival has become a major event in the New South Wales regional calendar. The overwhelming success of this regional event, and its largely favourable perception amongst both attendees and the host community, means that it serves as a beneficial case study.

\section{Survey method}

Two surveys were conducted to access both the attendees' perspective and the perspective of locals regarding the festival during the 2010 CountryLink Parkes Elvis Festival. A team of five researchers surveyed attendees on-site at the festival using a three page paper-based questionnaire. Some 371 festival attendees completed the questionnaire over the three-day period. The poll was conducted on a purely random basis, with no quota sampling applied. Both visitors and Parkes residents were interviewed. A 'next person past' method was used in approaching respondents. When approaching a couple or group, researchers asked one person to nominate himself/herself as the person to complete the interview.

The host community was surveyed two weeks after the festival using a random fixed line phone poll of 403 Parkes residents aged 18 years and over. Respondents were selected at random from a commercial database of 3,137 residential telephone numbers within the 2870 postcode, with no quota sampling applied. Potential respondents were screened to ensure they were aged 18 or over and had heard of the Parkes Elvis Festival. The survey time varied from 8 to 29 minutes, with an average of 12.8 minutes. Response rate was satisfactory, with approximately $48 \%$ of the eligible households contacted agreeing to participate.

\section{Attendee perspectives}

The attendee survey demonstrated the key demographics of those who attended the Parkes Elvis Festival in 2010 (see Figure 26.2). Over half of all respondents resided in regional New South Wales. One quarter of the respondents were from its capital, Sydney and 15\% were from interstate or overseas. $16 \%$ of attendees were from the local area. 


\begin{tabular}{|l|r|}
\hline Gender & \\
\hline Male & $36 \%$ \\
\hline Female & $64 \%$ \\
\hline Age & \\
\hline $18-24$ & $2 \%$ \\
\hline $25-34$ & $3 \%$ \\
\hline $35-44$ & $11 \%$ \\
\hline $45-54$ & $27 \%$ \\
\hline $55-64$ & $37 \%$ \\
\hline $65+$ & $20 \%$ \\
\hline
\end{tabular}

\begin{tabular}{|l|r|}
\hline \multicolumn{2}{|l|}{ Place of Residence $(\mathrm{n}=371)$} \\
\hline Regional NSW & $53 \%$ \\
\hline Sydney & $17 \%$ \\
\hline Parkes & $16 \%$ \\
\hline State of Queensland & $6 \%$ \\
\hline State of Victoria & $5 \%$ \\
\hline Other & $4 \%$ \\
\hline First time visiting the Festival $(\mathrm{n}=369)$ \\
\hline No & $53 \%$ \\
\hline Yes & $47 \%$ \\
\hline First time visiting Parkes? $(\mathrm{n}=314)$ \\
\hline No & $58 \%$ \\
\hline Yes & $42 \%$ \\
\hline
\end{tabular}

Figure 26.2: Parkes Elvis Festival attendee profile

\section{Who came?}

The Parkes Elvis Festival attracts an older demographic, with $84 \%$ aged over 45 years of age and $57 \%$ aged over 55. This is not surprising considering that Elvis was a music idol of the baby-boomer generation who are represented in these age groups. Additionally, retirees have the time for leisure pursuits and, in general, have the financial means to travel. Only $2 \%$ of attendees surveyed were aged between 18-24, 3\% aged between $25-34$ and $11 \%$ aged $35-44$. This demographic configuration poses a major concern for festival visitor numbers over the longer term as the baby boomer generation recedes.

Of those surveyed, over two-thirds were female. Retirees provided the largest group of attendees $(24 \%)$, as can be expected given the older demographic profile of all attendees. The remaining attendees had a wide variety of occupations with the second largest percentages after retirees listed as houseworker $(8 \%)$ and health care worker $(8 \%)$, followed by office/administration $(6 \%)$, teacher/trainer $(6 \%)$, manager (4\%), farmer (4\%) and business director/entrepreneur (4\%). Ministers, bankers, accountants, scientists and members of the military were also present, amongst others. Ultimately, aside from the large portion of retirees, the attendees came from a diverse range of professional backgrounds and sectors.

\section{How did they get there?}

The official mode of transport for the event was the 'Elvis Express', a Country Link train that leaves from Sydney's Central Station and travels directly to Parkes. The train ticket is a package deal that includes entertainment while on board, a souvenir programme and unlimited shuttle bus transportation within Parkes throughout the festival. While only $7 \%$ travelled to the festival on the train, it's 
an integral part of the event with the train's arrival at Parkes station signalling the start of the festivities. The excitement builds from the time its guests step on board (usually already in costume), singing and dancing their way to Parkes where they are greeted with much fanfare upon their arrival. The vast majority of visitors (83\%) travel to the event by car and, once in Parkes, made their way around town by walking $(78 \%)$.

\section{Accommodation}

With the festival resulting in a short-term boost to the population of Parkes, a variety of types of accommodation are used by visitors. 18\% stayed with friends or relatives, $17 \%$ camped or stayed in caravans and motorhomes, $15 \%$ were hosted in local homes, 15\% were accommodated in motels, hotels and cabins within Parkes, with another 13\% staying in a motel or hotel outside of Parkes. Finally, 10\% camped/caravanned at the Parkes showground.

\section{How many days they attended the festival}

Those interviewed were asked how many days they expected to attend the festival. A sizeable proportion of visitors (32\%) were planning to spend three days attending the festival, with a further $36 \%$ spending four days or more. Some stayed for shorter periods, with $15 \%$ for one day and $17 \%$ staying for two days.

\section{What they spent}

Average (estimated) expenditure for festival goers was \$256 (AUD) per person overall (includes local attendees), and \$280 (AUD) per head for visitors to Parkes. This implies a total contribution from the festival in excess of $\$ 3$ million (AUD). Main items of expenditure were event tickets, accommodation, meals, other entertainment, transport and personal services. Average per head spend on Elvis and/or festival merchandise was \$81 (AUD). With expenditure in New South Wales outside of Parkes Shire at \$688 (AUD) per person, the flow-on effect of the festival to other parts of regional NSW was quite high.

\section{Motivation for coming to the Parkes Elvis Festival}

Attendees were asked to rate ten motivations for attending the festival on a scale from 1-10, where 1 was 'Extremely unimportant' and 10 was 'Extremely important'. The major motivation was to 'play and have fun' (mean 8.52), closely followed by 'the music/entertainment' (8.51) and 'to escape from one's everyday routine' (8.0). The desire to 'experience a sense of community' (7.29) also ranked strongly. Interestingly these motivations all ranked higher than what would, on face value, be the most obvious motivation - that of being a fan of Elvis (7.02).

These results demonstrate the importance that 'play' has in fuelling the success of an event such as the Parkes Elvis Festival. Indeed one interviewer notes that 
when surveyed participants were asked if their motivation was to 'play and have fun' their faces would light up and they would say 'oh yeah! ... That one (that 'play and have fun' option)! That is what I'm doing!' Jonson et al (forthcoming) argue that the importance of 'play' in the festival's success has significance in how events and leisure are conceptualised on a broader scale. In the context of a postmodern environment where leisure is often regarded as depthless and potentially meaningless, spurred by notions of its inauthenticity, the Parkes Elvis Festival is a remarkable exception. By providing a playful space in which attendees can immerse themselves, the festival provides meaningful opportunities for socialisation and community bonding (Jonson et al, forthcoming).

When the motivation of 'play' is blended with notions of 'escaping the everyday', the attraction of the event becomes clear. With adoring 'fans' lining up to 'kiss Elvis', the element of 'play' provided a socially sanctioned opportunity to break standard boundaries. With many attendees dressing up in costume, the festival gives people permission to be playful and to get involved. In turn this built a sense of sociability and community, forging bonds between otherwise diverse individuals. The festival appealed to a wider audience than simply the Elvis fan base and provided a unique and inclusive experience, embraced by the vast majority of attendees.

Of those who attended the festival, $47 \%$ had been to the festival before, while $42 \%$ were visiting the town for the first time. All but $2 \%$ had travelled to Parkes specifically for the festival. The high level of repeat visitation reflects the overwhelmingly positive experience of attendees. One third were attending their second festival, while a loyal following of $7 \%$ had attended 15 or more.

Having explored the demographics and motivations of those who attended the Parkes Elvis Festival, we now turn our attention to the perception of the host community, a large proportion of whom also attended the festival.

\section{Host community perspectives}

Of the survey respondents, $60 \%$ had lived in Parkes for 20 years or more and thus prior to the founding of the festival. $69 \%$ of the respondents were female. All were over the age of 18 with $13 \%$ being $18-35$ years of age, $24 \%$ were $36-50,33 \%$ were aged $51-65$ and the remaining $30 \%$ were over $65 y$ years old. $71 \%$ of respondents had attended the 2010 festival and $85 \%$ had attended in previous years.

The host community survey explored residents' perceptions of the social and economic impacts of the festival. The festival was for the most part a source of great pride and fondness for local residents. Many of the respondents stated that they wanted the festival to continue in the future and get 'bigger and better' and when asked for a word to describe the festival the most popular word was 'great!'. 


\section{Economic effects}

Festivals of one kind or another play an important role in the economic and social development of regional communities. Festivals are generally seen as increasing economic activity and creating new jobs resulting from the net increase in demand for goods and services they generate. The attendee survey indicated that the expenditure injected into Parkes Shire as a result of the festival exceeded \$3 million (AUD). This expenditure equates to sales revenues of local businesses in respect of ticket sales, accommodation, meals, other entertainment, transport and personal services. In an unprompted question, respondents listed benefits to the economy (51\%) and impacts on tourism flows (36\%) as the two major positive impacts of the festival. One respondent remarked upon the positive impact of the festival and how "it brings so much outside money into the district... the fact that we are able to double the population in one weekend has a huge positive impact upon the whole town." Another claimed that because Parkes is a rural town, the place can get "very sad after Christmas and the shops get poor". The Elvis Festival (in the second week of January) "boosts the economy back up and provides a lovely and happy atmosphere". Underlying the economic benefits accruing from such an event, more than one-third of respondents said that they had worked extra hours as a result of the festival. Comments demonstrated that the festival was perceived as a positive stimulus for employment and skills creation. Certain concerns were evident, however. One respondent argued that growth of the festival had potentially cut out the ability of some local community members to participate. He complained that his wife used to have a stall but as the event has become more commercial, many of the smaller stallholders can no longer afford to rent a stall space. Another stated simply that the festival only benefits a certain number of businesses.

Over the longer term, increased tourism flows to Parkes as a result of hosting the festival can lead to growth of existing businesses, the establishment of new ones, and the development of a more skilled workforce. There is evidence that the hosting of successful festivals is associated with increased business confidence (the business counterpart to increased civic pride), inducing greater business activity including increased business investment, and induced construction and development expenditure (Jago et al., 2003; Newbold et al., 2015). Organisers may wish to find ways to ensure that more businesses, both small and large, can benefit from the festival.

\section{Social impacts}

While the Parkes Elvis Festival was a boost to tourism and the economy of the region, much of the fondness that it generated was directed towards the positive impacts it had in terms of building a sense of community and bringing people together. As a rural town with some economic disadvantage, and, at the time of the survey, in the midst of a drought, there was an overwhelming sense that the festival provided a morale boost for locals, even providing them with a "reason 
to get out of bed for the weekend". It provided the local residents with an escape from their everyday lives, just as it provided the visitors with the opportunity to escape theirs. One respondent perhaps summed it up the best stating: "if (the festival) wasn't held, it would be a big hole - people would miss it".

Locals viewed the access to entertainment very positively, with $97 \%$ stating that this was one of the key impacts the festival provided to the local community. Another key impact, with $94 \%$ in agreement, was that the festival provided locals with the opportunity to meet new people, and 93\% enjoyed a shared experience with friends and family. Factors of social isolation were able to be overcome as the festival provided a means to bond with strangers, as well as drawing a large group of new people to the otherwise relatively isolated town. The festival was also perceived to raise local spirits, with comments such as "I love people at festival time - the festival is so good for the community", and "the festival is good for community spirit and brings people together". These comments demonstrate how the festival was perceived to help provide a means of social connection and create a sense of community within the town.

The festival also relies on local involvement. While most are likely to simply attend and to enjoy the jovial spirit, $10 \%$ of respondents worked as volunteers. A further $6 \%$ opened their homes to visitors in the 'home hosting' programme and $60 \%$ said they would consider doing so in the future. This community involvement helps the festival to continue, providing a source of volunteer labour and helping alleviate the difficulty of accommodating such large numbers of event tourists. The community support provides a backbone to the festival, both in terms of providing a welcoming environment for the festivities to successfully take place as well as the practicality of running the event.

Nearly every respondent agreed that the festival enhanced Parkes' reputation (98\%), and 91\% said it increased the sense of pride that locals felt towards their town. There was also a clear sense that it helps raise awareness of Parkes and it was frequently mentioned that the festival "put Parkes on the map". A resident explained that when they visited Western Australia (a state on the opposite side of the country to New South Wales) they were amazed that so many people knew of the festival. The fact that it was not just a regional or national reputation also proved exciting, with one local proudly commenting about how they were told by a German visitor that out of all the Elvis festivals she had been to overseas, the Parkes Elvis Festival was the best.

While the majority of responses were overwhelmingly positive in their attitudes toward the social impacts of the festival, there were limited concerns regarding some negative impacts upon the local community. For example, 11\% complained that the festival increased rowdy behaviour, yet $72 \%$ said this was not a problem and $17 \%$ remained unsure. There was slightly less consensus regarding concern that the festival encouraged excessive drinking and/or drug use with $16 \%$ agreeing that this was a problem, $52 \%$ said it was not and $33 \%$ remained unsure. 
A more common concern was that the festival did not appropriately provide for people with disabilities. For example, the main entertainment area, Cooke Park proved difficult for wheelchair access. Others complained that some events were too crowded and therefore overwhelming for some people with autism or the elderly. Respondents suggested a few smaller events be included to cater for these special needs. Given that the festival attracts an ageing demographic, the need to cater for those with mobility, sight, hearing and other age-related disabilities is even more pressing. Accessible pathways around event and accommodation venues, and accessible transportation and facilities are areas that need further attention (Darcy and Harris, 2003). An additional concern that arose was that the festival had become too big for Parkes to accommodate/handle. Some respondents suggested it may need to move to a nearby larger town such as Dubbo or Forbes, while others strongly argued against this stating "the festival is great for Parkes, I hope Dubbo does not steal it!"

\section{Conclusions}

Clearly the festival has the support of the community. Given the importance of community support and involvement for any such event to be sustainable over time (Small, 2007; Schlenker et al., 2010) we can have confidence that the Parkes Elvis Festival will continue to attract visitors into the future. This case study has highlighted the benefits such a festival provides to the town of Parkes - it provides a space for visitors and locals alike to escape the everyday, to bond and to build community ties. The festival provides a unique product, one that does not have an obvious connection to its geographic location. Despite the lack of any tangible connection between Parkes and Elvis, the festival is an overwhelming success and continues to grow. In large part, this is due to its ability to embrace its eccentricity and to provide an inclusive space and a sociable environment.

For the festival to continue to deliver net benefits to locals, however, a number of issues need to be explored. One issue involves the economic effects of the festival, specifically the impacts on local income and employment. To date no economic impact study of the festival has been undertaken. As noted above, expenditure measures alone do not inform decision makers of the effects of the festival on the wider economy (Edwards et al., 2014). More research also needs to be undertaken to determine the role that the Parkes Elvis Festival can play in the destination branding of Parkes Shire and the extent to which it can be used to support the tourism marketing effort. To date no surveys targeted at business operators have been undertaken, despite their potential to generate very useful 'supply side' information on operator attitudes and strategies to maximise the economic effects of the festival. Gaps exist also in our understanding of the role played by professional performers and artists in the festival's success. Stakeholder support for any such festival should never be taken for granted by organisers and is essential for its future performance. 
As a final comment, the community plays an important role in ensuring successful implementation of events such as the Parkes Elvis Festival, particularly in respect of provision of hospitality and visitor safety and security. Hospitality relates not only to the provision of accommodation, food and beverage but also to the perceived friendliness of the local population and community attitudes towards visitors. While the perceived social effects are overwhelmingly positive at the present time, it is essential that festival convenors monitor community attitudes over time. The greater that local involvement is in the development of an event, the more likely residents are to feel a sense of 'ownership' of that event. Local participation in festival planning can help to forge business linkages between tourism activity and other, formal and informal, activity in the community to secure a vibrant and sustainable future for the Parkes Elvis Festival.

\section{Bibliography}

Darcy, S., and Harris, R. (2003) Inclusive and accessible special event planning: An Australian perspective, in Event Management: An International Journal, 8(1), 39-47.

Edwards, D. C., Schlenker, K., Foley, C. T., Hergesell, A., and Dwyer, A. (2014). Evaluating the economic contribution of a large indoor entertainment venues: an inscope expenditure study, in Event Management: An International Journal, 18(4), 407-420.

Foley, C., Schlenker, K., and Schweinsberg, S. C. (2011) Triple-Bottom-Line event evaluation and the 2010 CountryLink Parkes Elvis Festival, in J. Allen, W. O'Toole, R. Harris, and I. McDonnell (eds.), Festival and Special Event Management, Milton, Queensland: John Wiley and Sons Australia, 511-515.

Getz, D. (2010) The nature and scope of festival studies, in International Journal of Event Management Research, 5(1), 1-47.

Jago, L., Chalip, L., Brown, G., Mules, T., and Ali, S. (2003) Building events into destination branding: Insights from experts, in Event Management: An International Journal, 8(1), 3-14.

Jonson, P., Small, J., Foley, C., and Schlenker, K. (forthcoming) All shook up at the Parkes Elvis Festival: The role of play in events, Event Management: An International Journal, Special issue on 'Event Management and Society'.

Newbold, C., Jordan, J., Bianchini, F., and Maughan, C. (2015) Introduction: Focusing on festivals, in C. Newbold, C. Maughan, J. Jordan, and F. Bianchini (eds.), Focus on Festivals: Contemporary European Case Studies and Perspectives, Oxford: Goodfellow, xv-xxvi.

Parkes Elvis Festival. (2015) Parkes Elvis Festival. Available: http://www.parkeselvisfestival. com.au/ [Accessed 13 July 2015].

Schlenker, K., Foley, C., and Getz, D. (2010) Encore Festival and Event Evaluation Kit: Review and Redevelopment, CRC for Sustainable Tourism, Gold Coast, Queensland, Australia.

Small, K. (2007), Social dimensions of community festivals: an application of factor analysis in the development of the Social Impact Perception (SIP) scale, in Event Management: An International Journal, 11(1-2), 45-55. 